\title{
Experiment reveals deficits in European regulation
}

An advisory body to the Spanish Ministry of Health $(\mathrm{MoH})$ is to investigate the part played by a Spanish scientist in experiments published in the May issue of the journal Human Reproduction. Carmen Mendoza, professor at the Department of Biochemistry and Molecular Biology of the University of Granada, is thought to have carried out research involving human oocyte nuclear transfer without permission, which is against Spanish law. The case highlights differences in the regulation of human fertility experimentation across Europe. Immediately following publication of the articlewhich reports alternative methods for human oocyte nuclear transfer into enucleated oocyte cytoplasts, aimed at alleviating infertility due to deficient ooplasmic factors-the Commission on Assisted Reproduction (CNRA) announced that it had received no request from Mendoza to authorize the work and that it was opening an investigation into the issue. Javier Rey, the CNRA's general secretary, told Nature Medicine that although Spanish law allows research on gametes, it prohibits their use in creating pre-embryos (up to 14 days after fertilization). Ironically, as no attempts were made to fertilize the oocytes in the experiment, Mendoza's group could probably have obtained permission for the study if they had applied. They did not. "Mendoza has committed a grave law infringement and, accordingly, she or her department may be penalized," he says.

Speaking to the Spanish media, Mendoza explained she had not requested authorization "because the human oocyte assays were not done in Spain but in Italy...so the CNRA had nothing to authorize." She has demanded a public apology from the commission, saying, "If not, I'm prepared to sue." She told Nature Medicine that the MoH has already opened proceedings against her, her department and the Faculty of Sciences of the University of Granada.

In the paper, the group writes that it made no attempt to test the fertilization ability and post-fertilization developmental potential of the reconstituted oocytes because the formation of human embryos for research purposes is banned by law in France and Spain, and is subject to strict regulation in Italy.

However, Mendoza says "that to take the research a step further" they have to search for places where laws are not prohibitive. The lead investigator of the group, Jan Tesarik, who is also Mendoza's husband, is now looking into the possibility of carrying out fertilization experiments of reconstituted oocytes in Brazil, because this country, he says, has no legal constraints on this type of research. Tesarik points out that he could also conduct these experiments in the UK.

\section{Xavier Bosch, Barcelona}

\section{No dismissal for hate-mail author}

Being an accomplished medical researcher and teacher is sufficient to excuse behavior that includes destroying institutional equipment, harassing colleagues and lying to them and to superiors-at least at the University of Toronto (UoT) and at the Hospital for Sick Children (HSC) in Toronto. This is the conclusion reached by a panel investigating the misconduct of Gideon Koren and recorded in a report signed by UoT president Robert Prichard and HSC president and CEO Michael Strofolino.

Between October 1998 and May 1999, Koren sent anonymous hate mail to colleagues regarding Nancy Olivieri's clinical trials of the drug deferiprone. After denying that he was the author, and impeding an independent investigation into the situation initiated by HSC, Koren was eventually trapped by DNA evidence from the anonymous correspondence (Nature Med. 6, 364; 2000). But although a nine-page report says that Koren's actions “...constitute gross misconduct and provide sufficient grounds for dismissal," the penalty of discharge has been mitigated based on Koren's hitherto-unblemished career record.

Instead, his punishment involves repayment of CAN\$35,000 (US $\$ 23,500$ ) over five years to the HSC as part of the cost of the investigation; removal from the CIBC-Wood Gundy Children's Miracle Foundation Chair in Child Health Research and from the position of deputy director of the UoT Interdepartmental Division of Clinical Pharmacology; and a six-month suspension-including only two months without pay-that ends today. The report states, "Your lying triggered

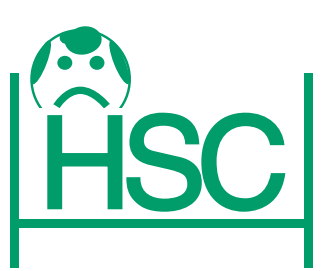

into Olivieri's claims that the HSC did not support her in trying to make discoveries about deferiprone public.

Koren claims to have sent two letters to Olivieri on 18 December 1996 and 8 February 1997. However, it is thought that these letters were actually prepared at a later date to buttress Koren's submission to the Naimark inquiry and to discredit Olivieri. The report states that the case on this allegation is not closed and adds, "In throwing away the computer in which you typed these letters, you might have destroyed the evidence that could have an expensive investigation. You abused the trust reposed in you and failed to live up to your responsibilities."

In addition, the report states that "specific allegations of alleged research misconduct remain outstanding," and these have been referred to the dean of the Faculty of Medicine. It also returned an open verdict on allegations that Koren submitted false evidence to the 1998 inquiry by Arnold Naimark, a professor at the University of Manitoba, proved or disproved this allegation."

Bill Graham, president of the UoT Faculty Association, told Nature Medicine, "The [Koren] decision fails to ensure an harassment-free environment that is critical to scientific work... and that the hospital and the university have damaged themselves by their failure to protect academic freedom and prevent harassment of scholars."

A second HSC/UoT scientist, Sergio Grinstein, who admits to sending an 